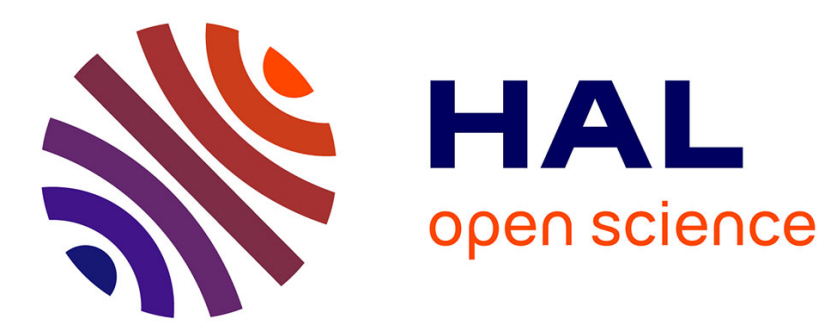

\title{
The Local Order of As Sites in Increasingly Amorphous $\mathrm{Si}$
}

\author{
A. Dent, G. Derst, G. Greaves, S. Kalbitzer, C. Klatt
}

\section{To cite this version:}

A. Dent, G. Derst, G. Greaves, S. Kalbitzer, C. Klatt. The Local Order of As Sites in Increasingly Amorphous Si. Journal de Physique IV Proceedings, 1997, 7 (C2), pp.C2-1207-C2-1208. 10.1051/jp4:19972196 . jpa-00255267

\section{HAL Id: jpa-00255267 https://hal.science/jpa-00255267}

Submitted on 1 Jan 1997

HAL is a multi-disciplinary open access archive for the deposit and dissemination of scientific research documents, whether they are published or not. The documents may come from teaching and research institutions in France or abroad, or from public or private research centers.
L'archive ouverte pluridisciplinaire HAL, est destinée au dépôt et à la diffusion de documents scientifiques de niveau recherche, publiés ou non, émanant des établissements d'enseignement et de recherche français ou étrangers, des laboratoires publics ou privés. 


\title{
The Local Order of As Sites in Increasingly Amorphous Si
}

\author{
A.J. Dent, G. Derst, G.N. Greaves, S. Kalbitzer* and C. Klatt* \\ C.C.L.R.C. Daresbury Laboratory, Warrington WA4 4AD, UK \\ * Max-Planck-Institut für Kernphysik, 6900 Heidelberg, Germany
}

\begin{abstract}
Our previous work has concentrated on the recrystallisation of amorphous silicon with temperature and we used XAFS to follow the local order of the dopants (typically As, Ga, etc) to see them change from essentially 3-fold in the amorphous state to 4-fold in the crystalline state. The main findings were that the silicon matrix recovers before the dopants can adjust their coordination numbers to the crystalline requirements. We present here investigations in the reverse process, namely, the progressive amorphisation of the crystalline matrix by ion bombardment. We show the progressive transformation of the dopants local structure as the matrix amorphises and show there is no delay in the structural tearrangement.
\end{abstract}

\section{INTRODUCTION}

In a series of XAFS studies of dopants in crystalline and amorphous $\mathrm{Si}[1,3,4]$, we have exploited high count rate multielement solid state detectors [5] and the use of glancing angles for the incident $\mathrm{X}$-rays [6] to detect changes in the environments of very small concentrations of dopants introduced by ion-implantation into semiconductor surfaces. The upshot has been that group $\mathrm{V}$ impurities like As which predominantly occupy 3-fold sites in amorphised surfaces only incompletely switch to tetrahedral substitutional sites when thermal epitaxial regrowth accurs around $550^{\circ} \mathrm{C}[4,7]$. This explains the structural reasons behind the delay in electronic reactivation until much higher temperatures are reached of typically over $1000^{\circ} \mathrm{C}$

We have now used the same empirical approach to examine the reverse process whereby the surface of commercial As-doped crystalline Si is gradually amorphised by ion beam damage.

\section{EXPERIMENTAL}

Crystalline silicon with bulk concentrations of $2.4 \times 10^{19} \mathrm{As} \mathrm{cm}^{-3}(0.05 \mathrm{wt} \%)$ were purchased from Wacker GmbH, Burghausen, Germany. The material was then ion implanted to a depth of $\sim 1.2 \mu \mathrm{m}$ using a combination of $1.9 \times 10^{15} 760 \mathrm{keV} \mathrm{Si}^{+} \mathrm{cm}^{-2}+$ $0.76 \times 10^{15} 320 \mathrm{keV} \mathrm{Si}^{+} \mathrm{cm}^{-2}$ ions to provide an approximately rectangular damaged layer. The absolute number of implanted ions was varied as $0 \leq x \leq 1$ where $x=1$ is the full dose described above. For fluorescence XAFS experiments, angles of incidence corresponding to 1.5 times $\phi_{c}$, the critical angle for total external reflection, were used. These offered a $1 / \mathrm{e}$ penetration depth of around $0.6 \mu \mathrm{m}$ and resulted in some penetration into the undamaged substrate ( $20 \%)$. Although shallower angles would have reduced this contribution it would have been at the expense of the signal from the damaged layer. With the analysis described next the crystalline substrate component to the XAFS signal could be deconvoluted with confidence.

\section{DISCUSSION}

Figure 1 shows the changing As environment in crystalline Si with progressive amorphisation. There is a noticable alteration in the shells of nearest neighbour Si atoms. For the first shell this is due in part to the difference in Debye-Waller factors between the crystalline and amorphous sites $\left(0.004 \AA^{2}\right.$ compared to $0.008 \AA^{2}$ respectively) and in part to the change in coordination number from 4 to 3 . (The 1 st shell decreases from $2.40 \AA$ to $2.35 \AA$ as the amorphisation takes place.) Knowing these nearest neighbour environments the fraction of 4-fold substitutional sites (and therefore those that are electronically active) that are retained can be deduced. Independent information is also present in the outer shells of atoms which gradually disappear with increasing ion beam damage to point where they are not detectable in the fully amorphised state. We have employed the same environments for 4-fold substitutional crystalline sites and 3-fold amorphous sites that we established previously in studying the annealing properties of dopants in Si that were initially amorphous. The first of these was obtained by direct XAFS analysis of As thermally diffused into crystalline $\mathrm{Si}$ [1], which was also measured and analysed by. Allain et al. [2], and the second by direct XAFS analysis of As implanted in annealed amorphous Si [3]. By dual fitting of the two fixed local geometries allowing only the proportions of each to float we have been able to deduce the fraction of substitutional sites at each stage of the amorphisation process. $C$, the degree of crystallinity, can be measured by 2 methods: (i) calculated from the first shell 4 -fold crystalline coordination number $(C=N$ cryst $/ 4$ ) or equivalently using the outer shells coordination number $C=N$ outer $/ 12)$; (ii) calculated from the first shell 3-fold amorphous site $(C=N$ amor $/ 3)$. The mean value of these two methods was taken. 


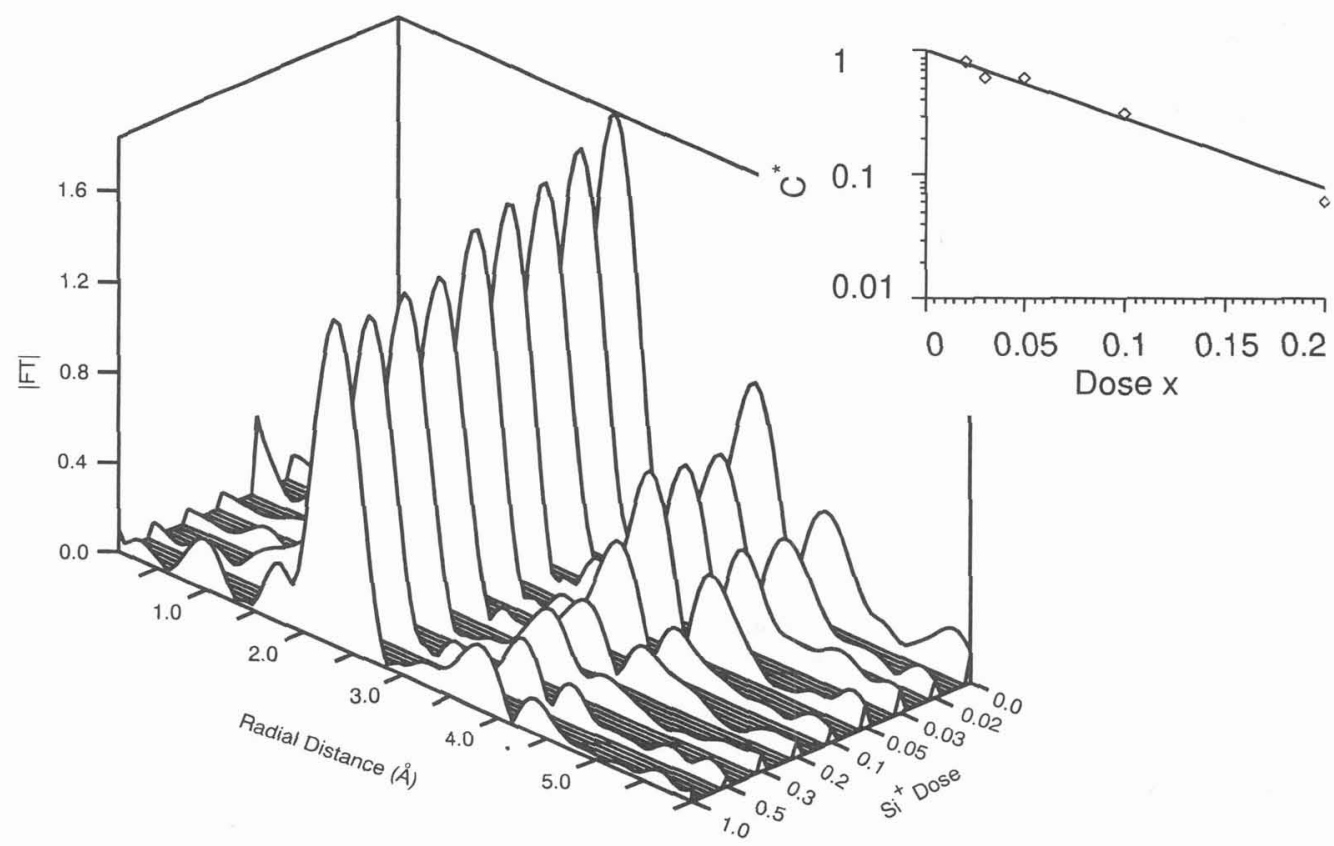

Figure 1: Fourier Transform moduli of the K-edge XAFS of As (0.05\%) present in commercial doped crystalline Si that has been gradually amorphised (see text for dose details) using polychromatic $\mathrm{Si}^{+}$ion beam damaging almost uniformly to a depth of ${ }^{\sim} 1.2 \mu \mathrm{m}$. The insert shows exponential decay of crystallinity as the dose is increased.

We find that local amorphisation process around the As sites is exponential with dose and is complete by the time that dose levels of approximately half the maximum dose quoted above are reached. This is consistent with the known rate of amorphisation of the bulk material [8]. The insert to figure 1 shows the log plot of crystallinity obtained against the dose $x$ defined above. $C^{*}$ is defined as:

$$
C^{*}=\frac{C-C_{\infty}}{C_{0}-C_{\infty}}
$$

where $C$ is the crystallinity derived from the above fitting process, $C_{\infty}$ the crystallinity obtained when the layer is completely amorphous (which is non-zero due to the X-rays penetrating below the $1.2 \mu \mathrm{m}$ amorphised layer) and $C_{0}$ is the crystallinity obtained from the starting material ( $~ 60 \%)$. This is intriguing, that the fraction of substitutional sites in the commercial starting material contains less than $100 \%$ substitutional sites. This type of doped $\mathrm{Si}$ is produced using a convoluted industrial process distinct from straight thermal diffusion - the process used to prepare the substitutional As site standard. Checks are currently being made to confirm the degree of underactivation independently from the present XAFS study, using a combination of electrical measurements and RBS channelling experiments.

\section{Conclusions}

The local order around the As sites was seen to decrease exponentially as the ion dose was increased and unlike the reverse crystallisation process instigated by heat treatment no delay in the amorphisation was seen.

\section{Acknowledgments}

The authors are grateful to the E.P.S.R.C. for financial support and the C.C.L.R.C. for access to the facilities of the Daresbury Laboratory.

\section{References}

[1] Greaves G.N., Dent A.J., Dobson B.R., Kalbitzer S., Pizzini S., Muller G., Phys. Rev. B45 (1992) 6517.

[2] Allain J.L., Regnard J.R., Bourret A., Parisini A., Armigliato A., Tourillon G., Pizzini S., Phys. Rev. B46 (1992) 9434.

[3] Greaves G.N., Dent A.J., Dobson B.R., Kalbitzer S., Muller G., Nucl Instr. \& Methods B80/81 (1993) 966.

[4] Mulier G., Kalbitzer S., Greaves G.N., Phil. Mag. (in press 1996)

[5] Farrow R.C., Derbyshire G.E., Dobson B.R., Dent A.J., Bogg D., Headspith J., Lawton R., Martini M., Buxton K., Nucl. Instr. \& Methods B97 (1995) 567.

[6] Greaves G.N., Advances in X-ray Analysis 34 (1991) 13.

[7] Kalbitzer S., Greaves G.N., Dent A.J., Derst G., Muller G., Nucl. Instr. \& Methods B97 (1995) 312.

[8] Kalbitzer S., Private Communication. 